\title{
Comparative and Stability Study of Glucose Concentrations Measured in both Sodium Fluoride and Serum Separator tubes
}

Authors: Mustapha Dibbasey1, Cathy Price2, Bolarinde Lawal1, Solomon Umukoro1

1. Medical Research Council@London School of Hygiene and Tropical Medicine

2. St Georges University of London

\section{Abstract}

Introduction: Sodium fluoride/potassium oxalate (NaF/KOx) tubes were once regarded as the gold-standard tubes for glucose analysis. Even though their ineffectiveness in immediately inhibiting glycolysis has been reported in several studies especially in the first 1-4hours, they are still used in our clinical Biochemistry laboratory for glucose measurement. However in its absence, only SSTs are employed for glucose measurement.

Aim: To determine whether SSTs can replace NaF/KOx tubes for laboratory-based measurement of blood glucose and to assess the stability of glucose concentrations for 3 days period

Methods: During the study period (1 March to 11 April, 2015), a total of 50 paired samples collected separately in NaF/KOx tubes and SSTs from healthy adult participants in the Gambia Adults Reference Intervals Study (GARIS) project were used as the project sample size. The samples were analysed within 2 hours, and at 24 hours, 42hours and 72hours time-points following blood collection and separation using Vitros 350 dry chemistry analyser. The GARIS samples were treated as clinical samples.

Results: There was no significant difference in the mean glucose concentrations between the two tubes (Mean difference $=0.06 \mathrm{mmol} / \mathrm{L} ; \mathrm{P}=0.38$ ) recorded in the different timepoints. Using growth trajectory and mixed effects model, the study data showed no significant change in the glucose concentrations $(p=0.25)$ for three days period.

Conclusions: The study confirms that SSTs can produce similar glucose results when employed in the absence of $\mathrm{NaF} / \mathrm{KOx}$ tubes. Besides, the glucose concentrations were stable in both tubes for three days when the samples were separated within two hours and refrigerated in $2-8^{\circ} \mathrm{C}$.

Keywords: Blood glucose; Sodium fluoride tubes; Serum separator tubes/serum gel tubes

\section{Abbreviations:}

SSTs: Serum Separator Tubes

NaF/KOx: Sodium fluoride/potassium oxalate

WHO: World Health Organisation

ADA: American Diabetes Association

EDTA: Ethylenediamine tetra acetic acid 
GARIS: Gambia Adults Reference Interval Study

NaF: Sodium Fluoride

MRC: Medical Research Council

ATP: Adenosine Triphosphate

GARIS: Gambia Adult Reference Interval Study

HIV: Human Immunodeficiency Virus

VDRL: Venereal Disease Research Laboratory

RBCs: Red Blood Cells

$\leq$ : Less than or equal to

z: Greater than or equal to 


\section{Introduction}

Laboratory-based measurement of blood glucose concentration is the gold-standard approach for diagnosis, treatment and assessment, and in the identification of patients at risk of developing diabetes mellitus. Diabetes mellitus (DM) is a group of metabolic disorders characterised by chronic hyperglycaemia resulting from defects in insulin synthesis, insulin action, or both (WHO, 2014). DM is a global health burden and accounts for $3.6 \%$ of the annual health budget of The Gambia (Rolfe et al., 1992). In 2014, WHO (2015) estimated the global prevalence of DM to be $9 \%$ among adults at least 18years of age and forecasted the disease to be the 7th leading cause of death in 2030 as the global prevalence of diabetes is projected to increase from 171 million in 2000 to 366 million in 2030 (Wild et al., 2000).

\section{NaF/KOx Tubes Effectiveness}

The increase prevalence of DM has made glucose one of the most commonly requested biochemical analytes worldwide. Glucose is an unstable molecule in the whole blood due to the impact of glycolysis (Gambino, 2007), a metabolic pathway which converts glucose molecule into pyruvate (Higgins, 2007). For many decades, NaF/KOx tubes were the goldstandard collection tubes of choice when accurate glucose measurement was required. The tube type containing a combination of sodium fluoride (NaF) and potassium oxalate (KOx) was primarily designed to immediately inhibit glycolysis which negatively affects final glucose concentrations. However, several recent findings have criticised the effectiveness of NaF/KOx tubes, especially in the first 1-4hours (Chan, Swaminathan and Cockram, 1989;Roux et al., 2004;Peake et al., 2013). Mikesh and Bruns (2008) indicated that complete inhibition of glycolysis by fluoride can take as long as four hours during which time glucose can decrease as much as $0.6 \mathrm{mmol} / \mathrm{L}$ at room temperature. Gambino (2009) criticised the false notion that $\mathrm{NaF} / \mathrm{KOx}$ tube is an effective glycolysis inhibitor in the absence of early centrifugation following blood collection. This criticism was proven by Gambino et al. (2009) study which reported that the mean glucose concentration reduced by $4.6 \%$ at two hours and by $7.0 \%$ at 24 hours when blood was drawn into NaF/KOx tubes, indicating a pre-analytical loss. Furthermore, other studies including Waring, Evans and Kirkpatrick, (2007), Turchiano et al., 2013, and Shi et al., 2009 have shown that early centrifugation of blood samples in lithium-heparin and SSTs produced higher mean glucose concentration than the mean glucose concentration of NaF/KOx tubes. Elleri et al., (2009) reported a decrease in blood glucose by $0.47 \mathrm{mmol} / \mathrm{L}$ despite samples were collected in NaF/KOx tube and iced immediately. However, these studies' findings are contrary to the study of Spencer et al. (2011), which described NaF preservative to have a better stabilising effect on plasma glucose when centrifugation was performed within the first 30 minutes. Based on the findings from the studies, both ADA in 2011 and WHO discourage the use of $\mathrm{NaF} / \mathrm{KOx}$ tubes to control glycolysis (Sack et al., 2011).

\section{Glucose Concentrations Stability}

As part of ISO15189 accreditation process, stability study of glucose concentrations was included in the study to meet ISO15189:2012 requirements (ISO15189, 2012). Chan, Swaminathan, and Cockram (1989) further indicated that glucose concentrations were stable in $\mathrm{NaF} / \mathrm{KOx}$ tubes for at least three days under room temperature following plasma separation. Al-Kharusi et al., (2014) reported that following plasma and serum separation, glucose concentration was stable at $4^{\circ} \mathrm{C}$ for seven days or even longer. In the study of Cuhadar et al. (2012) glucose concentrations in SSTs were stable at $4^{\circ} \mathrm{C}$ for up to 72 hours when centrifuged within 30 minutes. Henceforth, stability of glucose concentrations 
in the whole blood collected in NaF/KOx tubes for 24 hours under room temperature and in the whole blood stored at $4^{\circ} \mathrm{C}$ were also reported (Oddoze, Lombard and Portugal, 2012).

\section{NaF/KOx tubes/SSTs}

The practical drawback of $\mathrm{NaF} / \mathrm{KOx}$ tubes is not only its ineffectiveness in immediate glycolysis blockage but specificity to only measurement of glucose concentrations in blood and cerebrospinal fluid samples. However, SSTs have shown to be suitable for laboratory analysis of a wide spectrum of clinical chemistry analytes including blood glucose. The SSTs contain a gel which separates serum from cellular components, thus abrogating glycolysis. When compared to NaF/KOx tubes, a study conducted by Turchiano et al., (2013) demonstrated that mean glucose concentration for SSTs where significantly higher than the mean glucose concentration for NaF/KOx tubes whilst Frank, Shubha and D'Souza (2012) reported SSTs mean glucose concentration to be $1.15 \%$ lower than $\mathrm{NaF} / \mathrm{KOx}$ mean glucose concentration when analysis was performed within 10minutes after blood collection. Gambino, (2013) demonstrated that glucose concentration in $61 \%$ of the serum samples collected in SSTs was greater than the glucose concentration in the paired plasma samples collected in NaF/KOx tubes. Following the editorial support of the study conducted by Fernandez et al. (2013), which reported no difference in glucose concentrations in samples collected in both NaF/KOx tubes and SSTs in field condition and separated within 2hours of blood collection, Bruns (2013) questions the need for NaF/KOx tubes for blood glucose analysis. Li et al., (2013) and Al-Kharusi et al., (2014) further suggested both NaF/KOx tubes and SSTs to be suitable candidates for glucose measurement. Currently, SSTs are used for laboratory-based measurement of blood glucose in the absence of $\mathrm{NaF} / \mathrm{KOx}$ tubes in our Biochemistry laboratory. As such, the study aims to determine whether glucose concentrations will be varied significantly in the paired $\mathrm{NaF} / \mathrm{KOx}$ and SSTs samples and to assess the stability of glucose concentrations for 72 hours.

\section{Aim}

To determine whether SSTs can replace NaF/KOx tubes for laboratory-based measurement of blood glucose and to assess the stability of glucose concentrations for 3 days period

\section{Hypothesis}

$\mathrm{H}_{0}=$ there will be no significant difference in the glucose concentration measured using both $\mathrm{NaF} / \mathrm{KO}$ tubes and SSTs

$\mathrm{H}_{1}$ : there will be a significant difference in the glucose concentration measured using both $\mathrm{NaF} / \mathrm{KOx}$ tubes and SSTs

\section{Materials and Methods}

\section{Sample Collection/Handling}

The study was conducted in the Medical Research Council's (MRC) Biochemistry laboratory. With the permission of the study investigators, the blood samples for the practical project were obtained from the GARIS project which started in March 2015, an on-going project targeting to establish haematological and biochemical reference values for Gambian adults in Greater Banjul Area. During the practical project (1 March to 11 
April, 2015), a total of 50 pairs samples collected separately in NaF/KOx and SSTs from healthy adult participants in the GARIS project were used as the project sample size.

The participants who were healthy adult donors ( $\geq 18$ and $\leq 45 y e a r s$ ) residing in the urban areas and negative for HIV, VDRL and Hepatitis B were enrolled into the GARIS project. The participants were bled and the blood samples were received, in the clinical laboratories under room temperature.

Inclusion criteria: The first 50 pairs of GARIS samples with sufficient volume were used in the practical project.

\section{Sample analysis}

Prior to the analysis, quality controls were run to ascertain the functionality of the Vitros 350 Analyser, which performed the glucose analysis of the project samples. Centrifugation (separation of plasma from $\mathrm{NaF}$ blood and serum from clotted blood samples) and first analysis of glucose concentrations were performed within two hours of blood collection, and then the serum and plasma samples were stored at $2-8^{\circ} \mathrm{C}$ temperature. The subsequent analyses were exactly performed at the following time-points: 24,48 and 72 hours. The study samples were analysed using the same lot of reagent, eliminating any lot-to-lot variability in the results.

\section{Statistical analysis}

The statistical analysis was performed using STATA version 12 and Microsoft Word excel. Paired t-test was performed to determine any significant statistical difference in the mean glucose concentration recorded in the time-points. Pearson correlation was performed to determine the association between NaF/KOx tubes and SSTs glucose concentrations. A mixed effects model and growth trajectory were performed to assess the stability of glucose concentrations.

\section{Ethical Issues}

The GARIS project was approved by MRC Scientific Coordinating Committee and the Gambia Government/MRC Joint Ethics Committee (MRC, 2013) prior to commencement of the study. Written informed consent was obtained from study participants enrolled in the GARIS study. GARIS participants were assigned unique identification numbers for maintaining anonymity and confidentiality.

\section{Result}

Table:1 and figure:1 shows mean glucose concentrations (MGC) measured in both $\mathrm{NaF} / \mathrm{KOx}$ tubes and SSTs at different time-points. The total mean concentrations of $\mathrm{NaF} / \mathrm{KOx}$ tubes $(6.88 \pm 4.36 \mathrm{mmol} / \mathrm{L})$ and SSTs $(6.94 \pm 4.31 \mathrm{mmol} / \mathrm{L})$ produced an overall difference of $0.06 \mathrm{mmol} / \mathrm{L}$ [Total Mean difference $(\mathrm{NaF} / \mathrm{KOx}-\mathrm{SST})=0.06 \pm 0.07 ; \mathrm{n}=50$ ] . When the MGC from the time-points were compared using two-tailed paired t-test, the result shows no significant difference $(P=0.38)$. The Pearson correlation (Figure: 2$)$ shows high significant correlation $(\mathrm{R}=0.9999 \mathrm{P}<0.00001)$ between $\mathrm{NaF} / \mathrm{KOx}$ tubes and SSTs glucose concentrations. The $P$ value less that 0.05 indicates a statistical significant difference. 
Table 1: Showing MGC of NaF/KOx tubes and SSTs from different time-points

\begin{tabular}{llll}
\hline Time-points & $\begin{array}{l}\text { NaF/KOx } \\
\text { MGC }\end{array}$ & SST MGC & MD (NaF/KOx-SST)
\end{tabular}

within 2hrs

$6.86 \pm 4.31$

$6.88 \pm 4.34$

$6.87 \pm 4.38$

$6.92 \pm 4.38$

$6.88 \pm 0.07$

$6.94 \pm 0.07$

$-0.06$

72hrs

Total mean

$$
6.88 \pm 0.07
$$

$6.92 \pm 4.29$

$-0.06$

MGC: mean glucose concentration, MD: mean difference (i.e. differences between the time-points means), SST: serum separator tubes, $\mathrm{NaF} / \mathrm{KOx}$ : sodium fluoride tubes

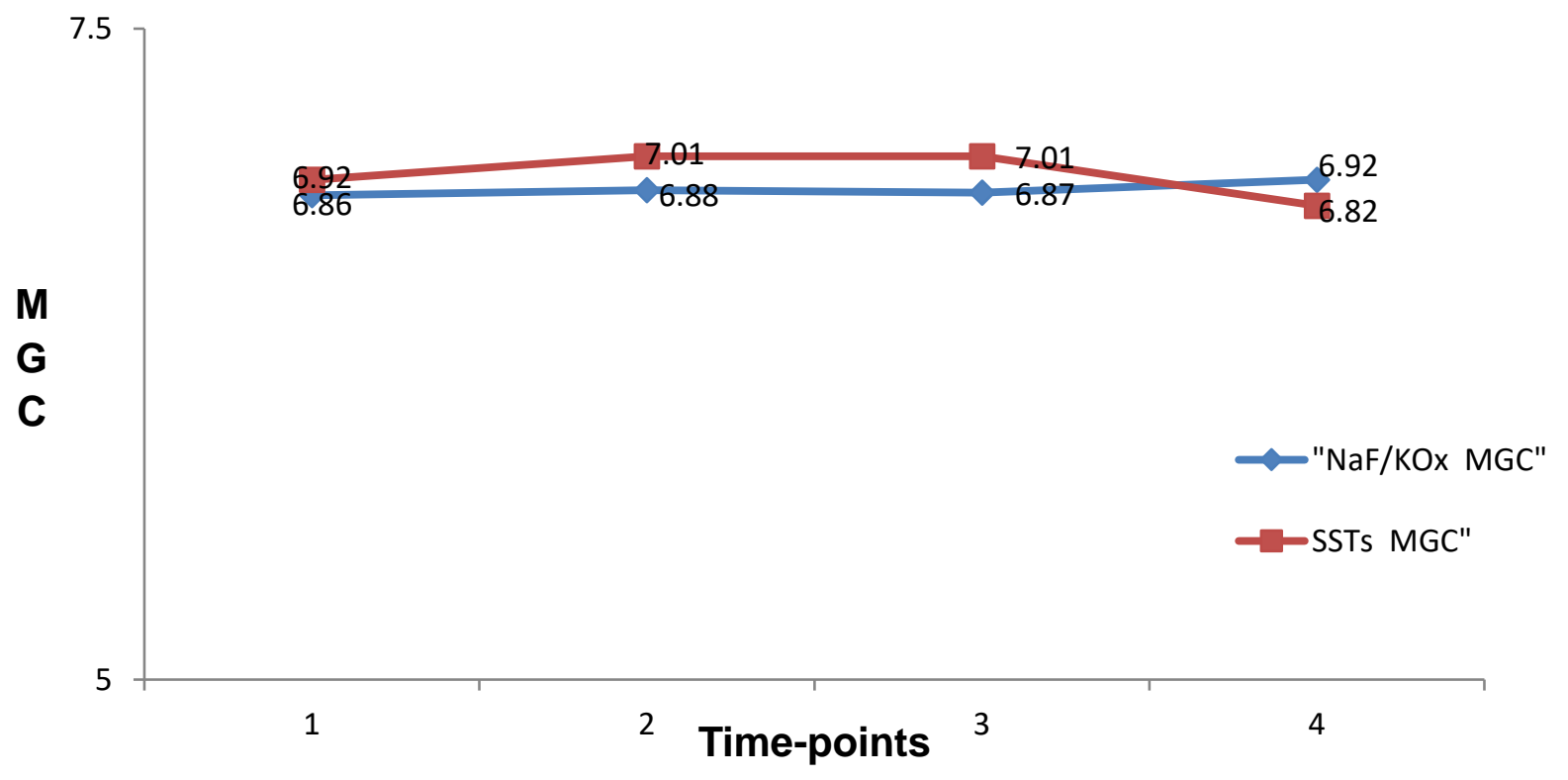

Figure 1: Graph showing the MGC of $\mathrm{NaF} / \mathrm{KO}$ tubes and SSTs recorded in the timepoints 1 (2hours), 2 (24hours), 3 (48hours) and 4 (72 hours) 


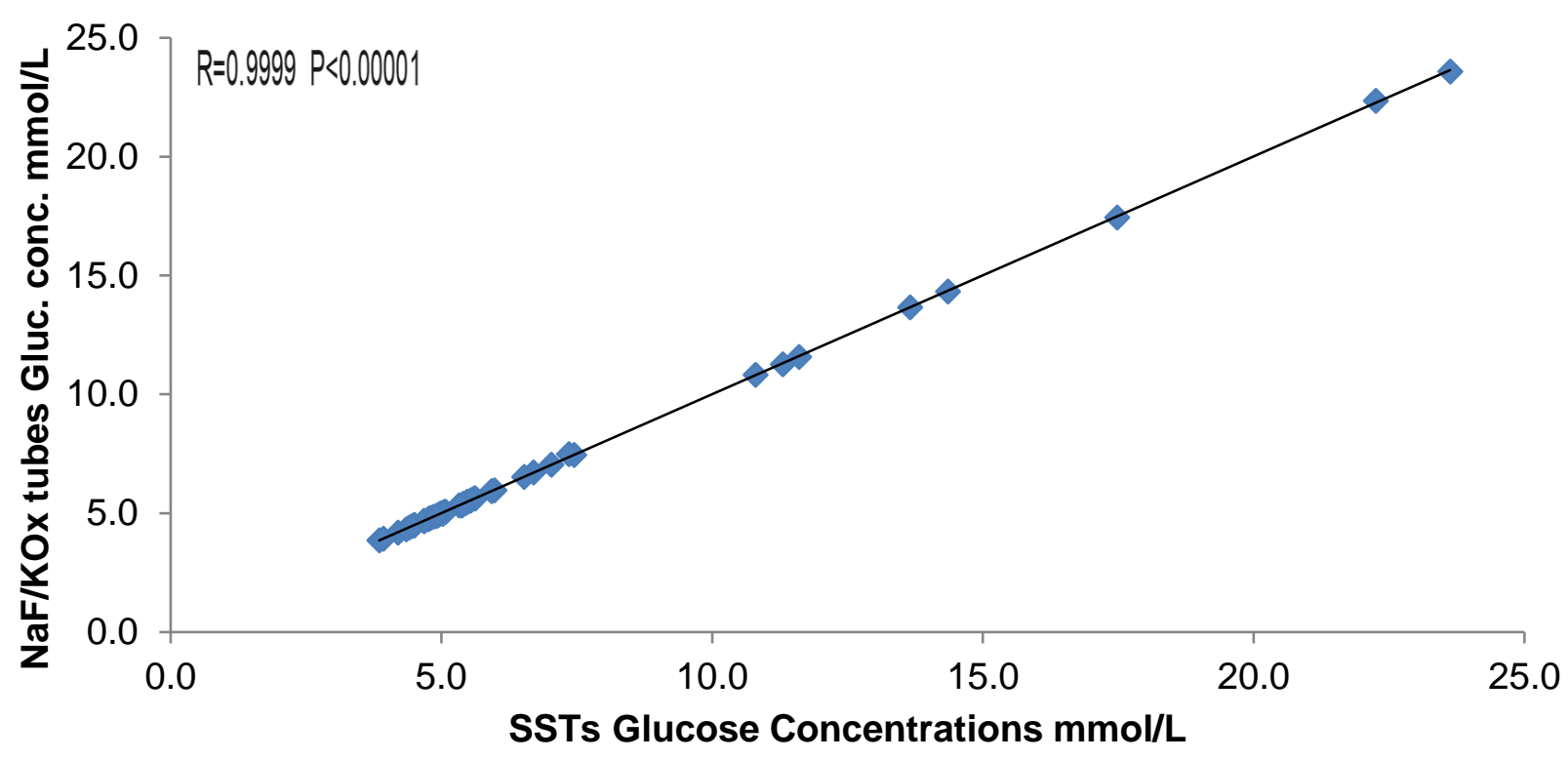

Figure: 2: Graph showing relationship between glucose concentrations meaured in $\mathrm{NaF} / \mathrm{KOx}$ tubes and SSTs

Growth trajectory graph (Figure:3) was used to determine the stability of individual glucose concentrations in both tubes after the first analysis and up to 72 hours of analysis. The graph shows that the glucose concentrations measured with $\mathrm{NaF} / \mathrm{KOx}$ and SSTs were stable from the first analysis up to 72 hours at $2-8^{\circ} \mathrm{C}$.
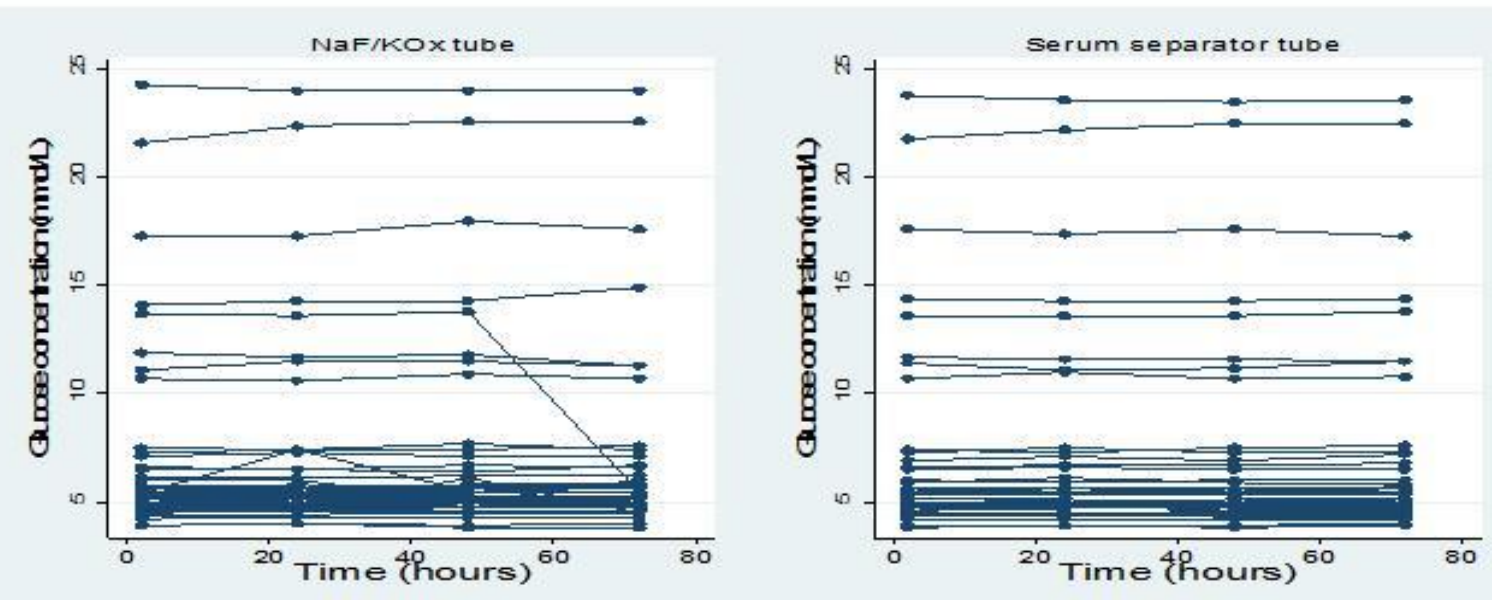

Figure 3: Growth trajectory graph for determining the stability of individual glucose concentrations from 2 to 72 hours

For statistical analysis purpose, raw glucose concentrations were transformed using the inverse of the square of the glucose concentration. Post-data transformation, a mixed effects model (Table:2) was employed for stability study of glucose concentrations in both tubes using within 2 hours as the reference category. There was no evidence of change in the glucose concentration (overall $p=0.25$ ) in both tubes for 3 days. 
bioRxiv preprint doi: https://doi.org/10.1101/2021.01.17.427029; this version posted January 19, 2021. The copyright holder for this preprint (which was not certified by peer review) is the author/funder, who has granted bioRxiv a license to display the preprint in perpetuity. It is made available under aCC-BY-NC-ND 4.0 International license.

Table 2: Stability study of glucose concentrations from the 2 hours to 72 hours of analysis

\begin{tabular}{lll}
\hline Time-points & Estimated difference $\left(95 \% \mathrm{Cl}^{*}\right)$ & p. value \\
\hline \multicolumn{1}{c}{ Within 2 hours" } & 0 & \\
& & \\
24 hours & 0.001 & 0.06 \\
48 hours & 0.0003 & 0.33 \\
72 hours & 0.0002 & 0.67 \\
Time & & $\mathbf{0 . 2 5}$ \\
\hline *: 95\% confidence interval. & \\
\#: Overall P. value & \\
": Reference category & \\
Discussion &
\end{tabular}

The study demonstrates no significant difference in the mean glucose concentrations between NaF/KOx tubes and SSTs. The study outcome is consistent with the outcome of the studies of Fernandez et al. (2013), Li et al., (2013) and Al-Kharusi et al., (2014), which qualify both tubes to be suitable candidates for glucose analysis. The slight increase in the SSTs MGC $(0.06 \mathrm{mmol} / \mathrm{L})$ as compared to $\mathrm{NaF} / \mathrm{KOx}$ tubes' explains the ineffectiveness of $\mathrm{NaF} / \mathrm{KOx}$ tubes and that the use of $\mathrm{NaF} / \mathrm{KOx}$ tubes may impact DM diagnosis especially for patients in borderline area of impaired glucose tolerance. Furthermore, this study, and other comparative and review studies have proven that the gold-standard tube is ineffective in its role to instantaneously block glycolysis (Gambino, 2007;Gambino et al., 2009;Mikesh and Bruns, 2008;Gambino, 2013;Bruns, 2013;Gambino and Bruns, 2013), hence its usage is being discouraged by ADA (Sack et al., 2011).

Since both tubes are suitable candidates as shown by the data (Table:1\&Figure:1), preference is given to SSTs as it can be used to analyse wide spectrum of biochemical analytes, and avoid inconveniencies and reduce mistakes associated with analysing both plasma and serum at the Biochemistry laboratory for an individual patient. Clinically, the use of only SSTs will reduce the volume of blood collected from patients when glucose and other analytes are requested together and improve glucose turn-around-time as well as laboratory workflow. Even with the low cost, elimination of NaF/KOx tubes would be a significant cost-saving measure for the National Health Service as large number of laboratory-based glucose tests are performed annually.

However, this study result differs from the previous studies including Gambino (2013), Waring, Evans and Kirkpatrick, (2006), Turchiano et al., (2013) and Shi et al., (2009), which reported higher significant differences in the MGC of SSTs as compared to the MGC of $\mathrm{NaF} / \mathrm{KOx}$ tubes. The significant difference was due to early separation as SSTs blood samples were centrifuged immediately after collection whereas $\mathrm{NaF} / \mathrm{KOx}$ samples were centrifuged immediately before glucose analysis. Since blood cells (erythrocytes, leucocytes and thrombocytes) are known to metabolise blood glucose, Mikesh and Bruns (2008) indicated that early separation of plasma/serum from the blood cells instantaneously abrogates glycolysis as the blood cells are prevented from metabolising blood glucose to glucose-6-phosphate and other phosphates. However, Frank, Shubha and D'Souza, (2012) found SSTs MGC to be lower than NaF/KOx MGC when analysis was performed within 10 minutes after blood collection. 


\section{Glucose Concentrations Stability}

After the first analysis, glucose concentrations were stable at $2-8^{\circ} \mathrm{C}$ in both tubes for three days. Similar finding was reported by Chan, Swaminathan and Cockram, (1989) even though the samples were stored in room temperature, Cuhadar et al. (2012) and AlKharusi et al., (2014). The stability of glucose concentrations after four hours in NaF/KOx tubes was explained in the study of Mikesh and Bruns (2008) which reported that NaF inhibits enolase within five minutes of addition to the blood while enzymes in the upstream of glycolysis pathway remain active, allowing continuous metabolism of glucose by blood cells into glucose-6-phosphate and other phosphorylated metabolites until there is no available supply of ATP in the cells. Supply of ATP is exhausted about 60 minutes after addition of $\mathrm{NaF}$ and then glucose concentration becomes stabilised in the tube (Gambino, 2007). In the case of SSTs, Bruns (2013) explains that SSTs contains gel barrier that separates blood cells from plasma, thus this means that glycolysis is completely ceased as soon as separation is performed. It further explains the stability of glucose concentrations in the SSTs (Shi et al., 2009;Mikesh and Bruns, 2008). The stability study hence proves that glucose concentration can be measured in plasma/serum within 3days when the samples are refrigeration at $2-8^{\circ} \mathrm{C}$.

\section{Limitations}

The study failed to address potential confounders such as diabetes status that can influence the observed results. From the study of Spencer et al. (2011), the data showed that plasma glucose in NaF/KOx reduced by 16.4 in non-diabetic and by 10.4 in diabetic patients.

Furthermore, it was not possible to estimate the effects of red blood cells (RBCs) haemolysis on glucose concentrations compared between the two tubes in the study. The studies of Fernandez et al., (2013), Al-Kharusi et al., (2014) and Ko et al., (2015) all reported high RBCs haemolysis in NaF/KOx tubes than in SSTs samples but failed to assess the impact of the haemolysis. This high haemolysis rate observed can potentially influence glucose concentration and might have resulted in the slight decrease in $\mathrm{NaF} / \mathrm{KOx}$ mean glucose concentration by $0.06 \mathrm{mmol} / \mathrm{L}$. Catalase released from the lysed erythrocytes can negatively affect glucose values (Lippi et al., 2006).

\section{Conclusion}

The study confirms that SSTs can be satisfactorily employed in the place of NaF/KOx tubes for laboratory glucose measurement in our settings. Accepting the use of SSTs for glucose measurement offers numerous operational benefits including cost-saving measure for the National Health Service. The glucose concentrations were stable in both tubes for three days when the plasma/serum samples were refrigerated at $2-8^{\circ} \mathrm{C}$. Further study is required to provide an insight into the effects of haemolysis on the glucose concentrations and its stability whilst considering potential confounders. 


\section{References}

Al-Kharusi, A. Al-Lawati, N. Al-Kindi, M. and Mula-Abed, W. (2014) 'Are tubes containing sodium fluoride still needed for the measurement of blood glucose in hospital laboratory practice?', Oman Medical Journal, 29(6), pp.404-407. doi: 10.5001/omj.2014.109

Bruns, D. E. (2013) 'Are fluoride-containing blood tubes still needed for glucose testing?', Clinical Biochemistry, 46(4-5), pp.289-290._DOI: 10.1016/j.clinbiochem.2013.01.009

Chan, A. Y. W. Swaminathan, R. and Cockram, C. S. (1989) 'Effectiveness of sodium fluoride as a preservative of glucose in blood', Clinical Chemistry, 35(2), pp.315-317

Cuhadar, S. Atay, A. Koseoglu, M. Dirican, A. Hur, A. (2012) 'Stability studies of common biochemical analytes in serum separator tubes with or without gel barrier subjected to various storage conditions', The Journal of Croatian Society of Medical Biochemistry and Laboratory Medicine, 22(2), pp.202-214. doi.org/10.11613/BM.2012.023

Elleri, D. Acerini, C. L. Allen, J. M. Larsen, A. F. Wilinska, M. E. Dunger, D. B. and Hovorka, R. (2009) 'Effect of delay on measurement of blood glucose levels in young subjects with type 1 diabetes', Diabetes Research and Clinical Practice, 86(2), pp.31-33. doi:10.1016/i.diabres.2009.06.025

Fernandez, L. Jee, P. Klein, M. Fischer, P. Perkins, S. L. Brooks, S. P. J. (2012) 'A comparison of glucose concentration in paired specimens collected in serum separator and fluoride/potassium oxalate blood collection tubes under survey 'field' conditions', Clinical Biochemistry, 46(4-5), pp.285-288. DOI: 10.1016/j.clinbiochem.2012.11.027

Frank, E. A. Shubha, M. C. and D'Souza, C. J. M. (2012) 'Blood glucose determination: plasma or serum', Journal of Clinical Laboratory Analysis, 26(5), pp.317-320. DOI: $10.1002 /$ jcla.21524

Gambino, R. (2007) 'Glucose: a simple molecule that is not simple to quantify', Clinical Chemistry, 53(12), pp. 2040-2041. doi: 10.1373/clinchem.2007.094466

Gambino, R. (2013) 'Sodium fluoride: an ineffective inhibitor of glycolysis', Annals of Clinical Biochemistry, 50(1), pp.3-5. DOI: 10.1258/acb.2012.012135

Gambino, R. Piscitelli, J. Ackattupathil, T. A. Theriault, J. L. Andrin, R. D. Sanfilippo, M. L. and Etienne, M. (2009) Acidification of Blood Is Superior to Sodium Fluoride Alone as an Inhibitor of Glycolysis', Clinical Chemistry, 55(5), pp.1019-1021. doi: 10.1373/clinchem.2008.121707

Higgins, C. (2007) Understanding laboratory investigations for nurses and health professionals. 2nd edn. UK: Blackwell Publishing Ltd

ISO (2012) ISO 15189:2012: medical laboratories -- requirements for quality and competence. Available at: https://www.iso.org/obp/ui/\#iso:std:iso:15189:ed-3:v2:en (Accessed: 31 May, 2015)

Ko, D. Won, D. Jeong, T. Lee, W. Chun, S. and Min, W. (2015) 'Comparison of red blood cell haemolysis plasma and serum separation tubes for outpatient specimens', Annals of Laboratory Medicine, 35(2), pp.194-197. doi: 10.3343/alm.2015.35.2.194 
Li, G. Cabanero, M. Wang, Z. Wang, H. Huang, T. Alexis, H. Eid, I. Muth, G. and Pincus, M. R. (2013) 'Comparison of glucose determinations on blood samples collected in three types of tubes', Annal of Clinical Laboratory Science, 43(3), pp.278-284

Lippi, G. Salvagno, G. L. Montagnana, M. Brocco, G. and Guidi, G. C. (2006) 'Influence of haemolysis on routine clinical chemistry testing', Clin Chem Lab Med, 44(3), pp.311-316. DOI: $\underline{10.1515 / C C L M .2006 .054}$

Mikesh, L. M. and Bruns, D. E. (2008) 'Stabilization of glucose in blood specimens: mechanism of delay in fluoride inhibition of glycolysis', Clinical Chemistry, 54(5), pp.59305932. doi: 10.1373/clinchem.2007.102160

Medical Research Council (2013) Guide on approval procedures. Available at: http://www.mrc.gm/partners/collaborations/guide-on-ethical-approval-procedures

Oddoze, C. Lombard, E. and Portugal, H. (2012) 'Stability study of 81 analytes in human whole blood, in serum and plasma', Clinical Biochemistry, 45(6), pp.464-469. doi:10.1016/j.clinbiochem.2012.01.012

Peake, M. J. Bruns, D. E. Sacks, D. B. Horvath, A. R. (2013) 'It's time for a better blood collection tube to improve the reliability of glucose results', Diabetes Care, 36(1), p.2. Doi: $10.2337 / \mathrm{dc} 12-1312$

Rolfe, M. Tang, C. M. Walker, R. W. Bassey, E. and George, M. (1992) 'Diabetes mellitus in The Gambia, west Africa', Diabetic Medicine: A Journal British Diabetes Association, 9(5), pp.484-488.

Roux, C. W. L. Wilkinson, S. D. Pavitt, D. V. Muller, B. R. and Alaghband-Zadeh, J. (2004) 'A new antiglycolytic agent', Annals of Clinical Biochemistry, 41(1), pp.43-46. doi: 10.1258/000456304322664681

Sacks, D. B. Arnold, M. Bakris, G. L. Bruns, D. E. Horvath, A. R. Kirkman, M. S. Lernmark, A. Metzger, B. and Nathan, D. M. (2011) 'Guidelines and recommendations for laboratory analysis in the diagnosis and management of diabetes mellitus', Diabetes Care, 34(6), pp.61-99._Doi: $\underline{10.2337 / \mathrm{dc} 11-9998}$

Shi, R. Z. Seeley, E. S. Bowen, R. and Faix, D. J. (2009) 'Rapid blood separation is superior to fluoride for preventing in vitro reductions in measured blood glucose concentration', Journal of Clinical Pathology, 62(8), pp.752-753 doi:10.1136/jcp.2008.062547

Spencer, N. C.O. Sunday. J. J. Erifeta, O. K. Georgina, O. Agbor, A. A. Esosa, U. S. and Jenevieve, O. (2011) 'Comparative stabilizing effects of some anticoagulants on fasting blood glucose of diabetics and non-diabetics, determined by spectrophotometry (glucose oxidase)', Asian Journal of Medical Sciences, 3(6), pp.234-236

Turchiano, M. Nguyen, C. Fierman, A. Lifshitz, M. and Convit, A. (2012) 'Impact of blood sample collection processing methods on glucose levels at community outreach studies', Journal of Environmental and Public Health, 2013(2013), pp.1-4. doi.org/10.1155/2013/256151

Waring, W. S. Evans, L. E. and Kirkpatrick, C. T. (2007) 'Glycolysis inhibitors negatively bias blood glucose measurements: potential impact on the reported prevalence of diabetes', Journal of Clinical Pathology, 60(7), pp.820-823. doi:10.1136/jcp.2006.039925 
WHO (2014) Diabetes Available at: http://www.who.int/diabetes/action online/basics/en/ (Accessed: 15 September, 2014)

WHO (2015) Diabetes. Available at: http://www.who.int/mediacentre/factsheets/fs312/en/ (Accessed: 17 May, 2015)

Wild, S. Roglic, G. Green, A. Sicree, R. and King, H. (2004) 'Global prevalence of diabetes', Diabetes Care, 27(5), pp.1047-1053. 